\title{
Conversion of Electrospun Chitosan into Chitin: A Robust Strategy to Tune the Properties of 2D Biomimetic Nanofiber Scaffolds
}

\author{
Natalia Toncheva-Moncheva ${ }^{1,2}{ }^{\infty}$, Abdelhafid Aqil $\left.^{1}{ }^{(}\right)$, Moreno Galleni ${ }^{3}$ and Christine Jérôme ${ }^{1, *}$ \\ 1 Center for Education and Research on Macromolecules (CERM), University of Liège, Cesam RU, \\ Allée du 6 août 13, Sart-Tilman, B6a, B-4000 Liège, Belgium; ntoncheva@polymer.bas.bg (N.T.-M.); \\ a.aqil@uliege.be (A.A.) \\ 2 Laboratory of Polymerization Processes, Institute of Polymers, Bulgarian Academy of Sciences, Akad. G. \\ Bonchev 103-A, 1113 Sofia, Bulgaria \\ 3 Laboratory of Biological Macromolecules, Center for Protein Engineering (CIP), InBioS, University of Liège, \\ Sart-Tilman, B6a, B-4000 Liège, Belgium; mgalleni@uliege.be \\ * Correspondence: c.jerome@uliege.be
}

Citation: Toncheva-Moncheva, N.; Aqil, A.; Galleni, M.; Jérôme, C. Conversion of Electrospun Chitosan into Chitin: A Robust Strategy to Tune the Properties of 2D Biomimetic Nanofiber Scaffolds. Polysaccharides 2021, 2, 271-286. https://doi.org/ 10.3390 /polysaccharides2020019

Academic Editor: Azizur Rahman

Received: 26 March 2021

Accepted: 26 April 2021

Published: 2 May 2021

Publisher's Note: MDPI stays neutral with regard to jurisdictional claims in published maps and institutional affiliations.

Copyright: (c) 2021 by the authors. Licensee MDPI, Basel, Switzerland. This article is an open access article distributed under the terms and conditions of the Creative Commons Attribution (CC BY) license (https:/ / creativecommons.org/licenses/by/ $4.0 /)$.

\begin{abstract}
New biomimetic micro- and nano-CsU-based fibrous scaffolds electrospun from solution containing high purity-medical grade chitosan (CsU) of fungus origin (CsU1, Mv 174,000 and CsU2, 205,000, degree of deacetylation (DDA) 65\%) and polyethylene oxide (PEO, Mv 900,000), in the presence of given amounts of Triton X-100 (from 0.01 to $0.5 \mathrm{wt} \%$ ) as surfactant were fabricated. We demonstrate that by carefully selecting compositions and surfactant levels, porous mats with CsU content up to $90 \%$ (at this molecular weight and DDA) were achieved. Remarkable long-term stability in water or phosphate buffer solution storage were obtained by developing post-electrospinning treatment allowing the complete elimination of the PEO from the CsU-fibers as demonstrated by TGA, DSC and ESEM analysis. Subsequent reacetylation procedure was applied to convert 2D biomimetic chitosan mats to chitin (CsE)-based ones while preserving the nanofiber structure. This innovative procedure allows tuning and modifying the thermal, mechanical properties and more importantly the biodegradation abilities (fast enzymatic biodegradation in some cases and slower on the others) of the prepared nanofibrous mats. The established reproducible method offers the unique advantage to modulate the membrane properties leading to stable $2 \mathrm{D}$ biomimetic $\mathrm{CsU}$ and / or chitin (CsE) scaffolds tailor-made for specific purposes in the field of tissue engineering.
\end{abstract}

Keywords: chitosan; chitin; fiber; electrospinning; 2D scaffold

\section{Introduction}

Chitin $(\mathrm{CsE})$ or poly $(\beta-(1 \rightarrow 4)$-2-acetamido-2-deoxy-D-glucopyranose] is an abundant and naturally occurring polysaccharide and one of the most popular and studied biopolymers [1]. CsE has a crystalline structure and is commonly found as a constituent of the exoskeleton of invertebrates as crustacean and molluscs [2]. Moreover, it is a main polymer component of the cell wall of some fungi and yeasts [3]. Extracted from mushroom waste at industrial scale, it offers the advantage of being an animal-free and well-controlled renewable material particularly attractive when biomedical applications are foreseen [4]. Being just behind cellulose in the amount of annual biosynthesis production, chitin leads to chitosan by deacetylation yielding to novel biomaterials (CsU) (Scheme 1) [5].

$\mathrm{CsU}$ is nontoxic, biodegradable and possesses antimicrobial properties that have led to significant research towards biological applications such as drug delivery, artificial tissue scaffolds for functional tissue engineering, and wound dressings [6]. Depending on the source and deacetylation method, the molecular weight ranges from 100 to over $1000 \mathrm{kDa}$ [7]. The degree of deacetylation (DDA) can vary between $30 \%$ and $90 \%$, thus allowing CsU solubilization in acidic media [8]. For application as tissue scaffolds, ability 
to form highly porous mats of micro and nanometer-sized fibers, such as those fabricated via electrospinning (ESP) is quite attractive [9]. CsU fibers possess an acetamido/amino functionality that imparts many biological properties along with possibilities of chemical modification and has remarkable affinity to proteins [10-12]. If poorly soluble in organic solvents [13], CsU has the advantage over chitin to be soluble in acetic-water mixtures that are not releasing toxic residues from the fibers [14]. Nevertheless, ESP of CsU with high degree of deacetylation is especially challenging because the amine groups protonated under acidic condition [15] make CsU a highly charged cationic polyelectrolyte, resulting in a high solution viscosity [16]. At low polymer concentrations (2-2.5 times above the entanglement concentration), it remains quite difficult to be electrospun due to the highly charged chains [17]. An alternative approach is the preparation of CsU:PEO blends, in which PEO helps the formation of the CsU fibers [18]. PEO was often selected, because it is highly soluble in water, could be used for producing ultra-fine fibers by ESP, and can form hydrogen bonds with polysaccharides [19]. However, a major limitation of CsU ESP is the sensitivity of the method, as well as the stability of the obtained protonated mats in aqueous media [20]. Apart the above described hitches, CsU ESP still remains very attractive for tissue engineering especially for skin repair [21]. In that field, CsU films, hydrogels and sponges appeared less efficient wound dressing as compared to electrospun nanofiber based 2D scaffolds [22-24].

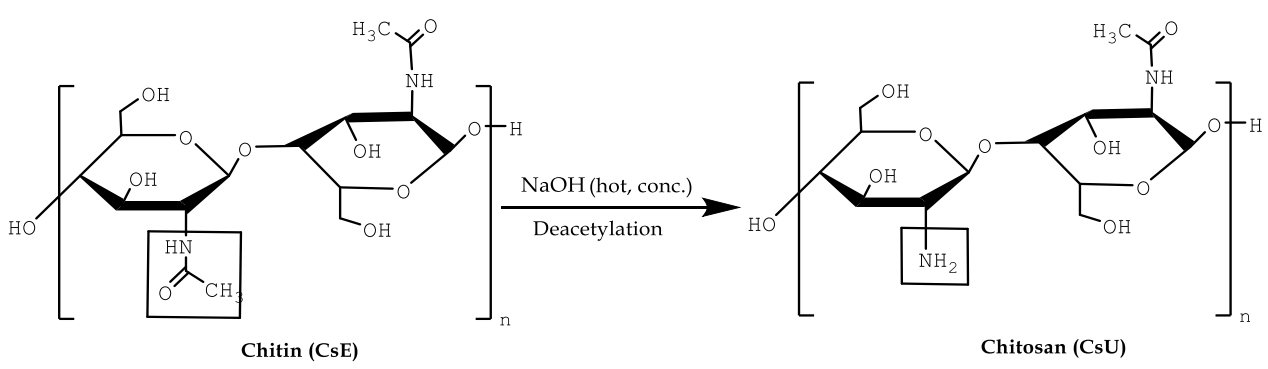

Scheme 1. Production of chitosan (CsU) by deacetylation of chitin (CsE).

The first aim of this paper is to report on a robust process for the formation of nonwoven mats of chitosan nanofibers, stable in water and in phosphate buffer by electrospinning of a high molecular weight and medical grade CsUs of fungus origin with average level of DDA $\sim 65 \%$. Furthermore, we investigated an acetylation procedure to convert the obtained 2D biomimetic chitosan mat to chitin-based one while preserving the nanofiber structure. This innovative process allows the tuning of the chemical, biodegradation, thermal and mechanical properties of the nanofiber nonwoven mats so that it can be tailored to fulfil the targeted tissue specificities.

\section{Materials and Methods}

\subsection{Materials}

Sodium ethoxide solution, $21 \mathrm{wt} \%$ in Ethanol, $\left(\mathrm{CH}_{3} \mathrm{CH}_{2} \mathrm{ONa}\right.$, Sigma Aldrich, Overijse, Belgium), Sodium ethoxide, $95 \%,\left(\mathrm{CH}_{3} \mathrm{CH}_{2} \mathrm{ONa}\right.$, Sigma Aldrich, Overijse, Belgium), Ethylene glycol diglycidyl ether, techn. $\left(\mathrm{C}_{8} \mathrm{H}_{14} \mathrm{O}_{4}\right.$, Sigma Aldrich, Overijse, Belgium), 1-4-butanediol diglycidyl ether, $\geq 95 \%,\left(\mathrm{C}_{10} \mathrm{H}_{18} \mathrm{O}_{4}\right.$, Sigma Aldrich, Overijse, Belgium), Calcium hydride, coarse granules, $95 \%\left(\mathrm{CaH}_{2}\right.$, Sigma Aldrich, Overijse, Belgium), Sodium Hydroxide, pellets for analysis, ACS reagent ( $\mathrm{NaOH}$, Merck, Overijse, Belgium), Sodium hydroxide $(\mathrm{NaOH}), \mathrm{MP}$ Biomedicals, Bruxelles, Belgium, anhydrous, (1534955, Fisher Scientific, Mechelen, Belgium), Sodium carbonate, $99.5 \%$, extra pure, anhydrous $\left(\mathrm{Na}_{2} \mathrm{CO}_{3}\right.$, Acros Organics, Gent, Belgium), Acetic acid 100\%, ACS reagent, ISO anhydrous GR for analysis $\left(\mathrm{CH}_{3} \mathrm{COOH}\right.$, Merck, Overijse, Belgium), Poly(ethylene oxide) (PEO)average $\mathrm{Mv}$ $\sim 900,000$, powder (189456, Sigma Aldrich, Overijse, Belgium), Triton ${ }^{\mathrm{TM}} \mathrm{X}-100$ BioXtra (t-Oct$\mathrm{C}_{6} \mathrm{H}_{4}-\left(\mathrm{OCH}_{2} \mathrm{CH}_{2}\right) \times \mathrm{OH}, \mathrm{x}=9-10$ Sigma Aldrich, Overijse, Belgium) were used as received. Ethanol-absolute, analytical grade reagent, $\left(\mathrm{CH}_{3} \mathrm{CH}_{2} \mathrm{OH}\right.$, Fisher Scientific, Mechelen, Bel- 
gium) was stored under molecular sieve $3 \AA ̊$. Deionized water was obtained by Millipore MilliQ system and was additionally filtered through a $220 \mathrm{~nm}$ PTFE filter. The chitosan samples were purchased from Kitozyme, Liege, Belgium (KiOmedine-CsU ${ }^{\circledR}$ CAS: [9012-76-4] is an ultra-pure chitosan of non-animal origin, produced from white mushrooms (Agaricus bisporus)). The main characteristics of both types of used chitosan are given Table 1.

Table 1. General information about the used medical grade CsUs.

\begin{tabular}{lccc}
\hline Chitosan Code & $\begin{array}{c}\text { Molecular Weight } \\
\text { (Mv) (g/mol) }\end{array}$ & $\begin{array}{c}\text { Degree of } \\
\text { Acetylation (mol \%) }\end{array}$ & $\begin{array}{c}\text { Apparent Viscosity (1\% } \\
\text { sol. in 1\% HAc) (mPa.s) }\end{array}$ \\
\hline CsU1 (L09306) & 174,000 & 32.3 & 115 \\
CsU2 (L10204) & 205,000 & 34.0 & 125 \\
\hline
\end{tabular}

\subsection{Mats Processing}

\subsubsection{Electrospinning Conditions}

Different solution compositions were prepared by dissolving appropriate amounts of chitosan in deionized water/acetic acid mixture, PEO in ultra-pure deionized water and gently stirring for $18 \mathrm{~h}$ (Scheme 2 and Table 2).

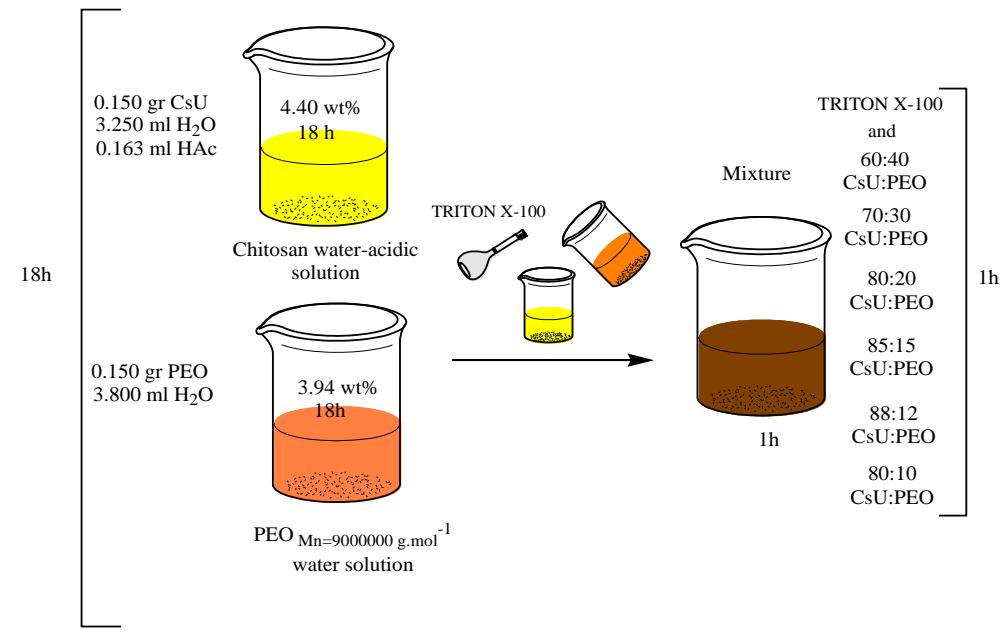

Scheme 2. Schematic representation of the ESP solutions preparation protocol.

Afterwards, solutions were mixed to the desired CsU:PEO ratio and a given amount of Triton X-100 was added (Table 2, Scheme 2). A total of $3 \mathrm{~mL}$ of the resulting wellhomogenized mixture were transferred into a plastic syringe equipped with orthogonally cut-ended needle (G 21 11/2", K51 Luer-lock, B. Braun Group, Italy). The solution was driven by syringe pump (Razel Scientific pump, Razel Scientific Instruments, Vermont, USA) at $1 \mathrm{~mL} \cdot \mathrm{h}^{-1} \mathrm{debit}$, and electrospinning voltage (by the use of Spellman SL10 power supply, model is 88906 (A-99)) ranging from 20 to $35 \mathrm{kV}$ was applied between the horizontal needle and a perpendicular fixed aluminum foil used as collector (Figure 1a). 

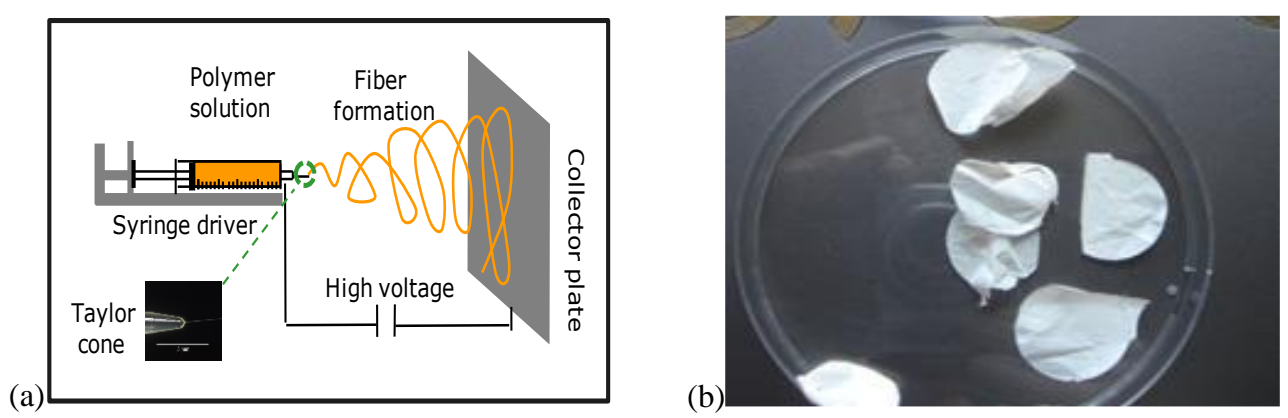

Figure 1. Electrospinning technique sketch (a) and collected CsU-based mats (b).

The temperature of $25{ }^{\circ} \mathrm{C}$ was selected for the ESP. The distance between the needle and the aluminum foil was $15 \mathrm{~cm}$. The electrospinning set-up was placed in a homemade box, equipped with UV lamp for ensuring sterilization. In order to collect easily defect-free nano-fibrous mats (Figure $1 \mathrm{~b}$ ) from the collector surface, the electrospinning was performed during 5-6 h. The different electrospinning conditions are summarized in Tables 2 and 3.

Table 2. Electrospinning conditions: solution composition and voltage.

\begin{tabular}{cccccc}
\hline $\begin{array}{c}\text { Mat Samples } \\
\text { Code }\end{array}$ & $\begin{array}{c}\text { Type of } \\
\text { CsU } \\
\text { Used }\end{array}$ & $\begin{array}{c}\text { Initial } \\
\text { CsU:PEO } \\
\text { Ratio }\end{array}$ & $\begin{array}{c}\text { Final } \\
\text { Solution } \\
\text { Conc. } \\
\mathbf{( w t \% )}\end{array}$ & $\begin{array}{c}\text { Triton X-100 } \\
\text { Conc. } \\
\mathbf{( w t \% )}\end{array}$ & $\begin{array}{c}\Delta \mathbf{V} \\
\mathbf{( k V )}\end{array}$ \\
\hline CN14 & & $60: 40$ & 4.22 & - & 27.0 \\
CN36 & CsU1 & $60: 40$ & 4.22 & 0.05 & 28.0 \\
CN64_65 & (L09306) & $85: 15$ & 4.32 & 0.20 & 30.0 \\
CN73 & & $88: 12$ & 4.33 & 0.20 & 34.0 \\
CN50 & & $90: 10$ & 4.34 & 0.40 & 31.0 \\
CN7_8A & CsU2 & $60: 40$ & 4.22 & 0.05 & 20.0 \\
CN5_6A & (L10204) & $85: 15$ & 4.32 & 0.10 & 28.0 \\
CN9_10A & & $88: 12$ & 4.33 & 0.20 & 30.4 \\
\hline
\end{tabular}

* $\mathrm{CsU}$ initial conc. $=4.40 \mathrm{wt} \%$ in solvent $\mathrm{HAc} / \mathrm{H}_{2} \mathrm{O}, \mathrm{PEO}$ initial conc. $=3.94 \mathrm{wt} \%$ in solvent deionized $\mathrm{H}_{2} \mathrm{O}$, Mixing time of CsU and PEO solutions $=1 \mathrm{~h}$, ESP time $=6 \mathrm{~h}$, Debit $1 \mathrm{~mL} \cdot \mathrm{h}^{-1}$, Distance between collector and the needle $=15 \mathrm{~cm}$, Temperature of $\mathrm{ESP}=25^{\circ} \mathrm{C}$.

Table 3. Electrospinning conditions for CsU1(L09306):PEO.

\begin{tabular}{cccc}
\hline Mat Samples Code & $\begin{array}{c}\text { Initial CsU:PEO } \\
\text { Ratio }\end{array}$ & Triton $\mathbf{X - 1 0 0}(\mathbf{w t} \mathbf{\%})$ & Voltage (kV) \\
\hline CN32 & & 0.5 & 22 \\
CN36 & $60: 40$ & $0.05^{* *}$ & 25 \\
CN34 & 0.03 & 26 \\
CN33 & 0.01 & 25 \\
CN41 & $70: 30$ & $0.1^{* *}$ & 25 \\
CN48 & & 0.05 & 27 \\
CN40 & $80: 20$ & $0.1^{* *}$ & 27 \\
CN47 & & 0.3 & 27 \\
CN49 & $85: 15$ & $0.2^{* *}$ & 28 \\
CN46 & & 0.1 & 27 \\
CN73 & $88: 12$ & $0.2^{* *}$ & 35 \\
CN43 & & 0.1 & 35 \\
CN44 & & 0.3 & 32 \\
CN50 & $90: 10$ & $0.4^{* *}$ & 31 \\
CN45 & & 0.5 & 27 \\
\hline
\end{tabular}

${ }^{*} \mathrm{CsU}$ initial conc. $=4.40 \mathrm{wt} \%$ in solvent $\mathrm{HAc} / \mathrm{H}_{2} \mathrm{O}, \mathrm{PEO}$ initial conc. $=3.94 \mathrm{wt} \%$ in solvent deionized $\mathrm{H}_{2} \mathrm{O}$ mixing time of CsU and PEO solutions $=1 \mathrm{~h}$, ESP time $=6 \mathrm{~h}$, debit $1 \mathrm{~mL} \cdot \mathrm{h}^{-1}$, distance between collector and the needle $=15 \mathrm{~cm}$, temperature of ESP $=25{ }^{\circ} \mathrm{C}$. ${ }^{* *}$ Mat samples obtained with the most appropriate concentration of Triton X-100. 


\subsubsection{Stabilization of the Mats}

In order to impart stability in water and in PBS buffer solutions of the obtained mats, the as-spun membranes were treated with dry absolute $\mathrm{EtOH} / \mathrm{NaOH}(0.5 \mathrm{M})$ mixture for several minutes, followed by intensive washing with sterile water until neutral $\mathrm{pH}$ was obtained. Subsequently, the membranes were dried under vacuum.

\subsubsection{Reacetylation of the Mats}

In order to convert chitosan back into chitin, a reacetylation process was performed. The electrospun and stabilized chitosan mats were immersed for $1 \mathrm{~h}$ under stirring in a solution of $>99 \%$ acetic anhydride diluted 32 times in methanol. Then, the mats were rinsed three times in $10 \mathrm{~mL}$ of sterile water and dried under air (Scheme 3).
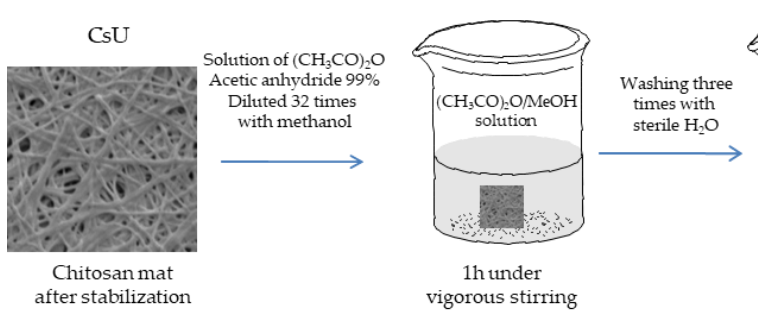

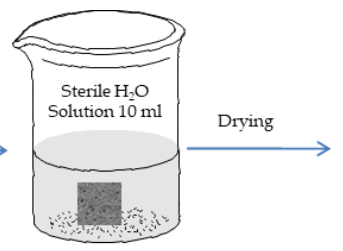

vigorous stirring

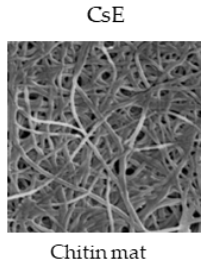

Scheme 3. Reacetylation reaction procedure of chitosan into chitin.

\subsection{Characterization Methods}

\subsubsection{Rheology}

Viscosity measurements on an ARES G2 Rheometer from TA instruments using a parallel plate geometry (gap diameter $25 \mathrm{~mm}$ ) equipped with a Peltier plate for temperature control (at $25^{\circ} \mathrm{C}$ ), soak time $10 \mathrm{~s}$, at a linear shear rate from 0.1 to $1001 \cdot \mathrm{s}^{-1}$ were performed. The data were collected with the TRIOS software.

\subsubsection{Scanning and Transmission Electron Microscopy}

Environmental scanning electron microscopy (ESEM JeolJSM-840A, Tokyo, Japan) to analyze the morphology, of as-spun CsU membranes was used. The produced fibers were metal coated by platinum before ESEM analysis.

\subsubsection{Differential Scanning Calorimetry (DSC)}

To sense the presence of PEO in the fiber mats, DSC (TA Instrument DSC Q100 V9.0 Build 275) was carried out in the $-50-150{ }^{\circ} \mathrm{C}$ temperature range, at a heating rate of $20^{\circ} \mathrm{C} \cdot \mathrm{min}^{-1}$ under a nitrogen flow $\left(50 \mathrm{~mL} \cdot \mathrm{min}^{-1}\right)$. Samples $(6.0 \pm 0.1 \mathrm{mg})$ were heated up to $150{ }^{\circ} \mathrm{C}$ at a rate of $20^{\circ} \mathrm{C} \cdot \mathrm{min}^{-1}$ (first scan) and then quenched to $-50{ }^{\circ} \mathrm{C}$ at a rate of $100{ }^{\circ} \mathrm{C} \cdot \mathrm{min}^{-1}$. Afterwards, they were heated again up to $150{ }^{\circ} \mathrm{C}$ (second scan) at a rate of $20^{\circ} \mathrm{C} \cdot \mathrm{min}^{-1}$. The melting temperature $\left(\mathrm{T}_{\mathrm{m}}\right)$ was defined as the temperature maximum of the melting endotherm.

\subsubsection{Thermal Gravimetric Analysis (TGA)}

A TGA Q500 V6.3 build 189 from TA Instruments was used in the range of $0-600{ }^{\circ} \mathrm{C}$ under a nitrogen flow of $40 \mathrm{~mL} \cdot \mathrm{min}^{-1}$. The heating rate chosen was $20^{\circ} \mathrm{C} \cdot \mathrm{min}^{-1}$ for conventional TGA and $40^{\circ} \mathrm{C} \cdot \mathrm{min}^{-1}$ in case of high-resolution TGA with a resolution parameter of 4 . Actually, the heating rate was continuously adjusted to track changes in the sample decomposition rate. This parameter was tuned within an eight-step scale to maximize the weight loss resolution. The $\pm 1{ }^{\circ} \mathrm{C}$ accuracy on the degradation temperature determined from the derivate of the weight losses temperature curve was established.

\subsubsection{Enzymatic Biodegradation}

In vitro biodegradation of chitosan and chitin fibrous mats was performed by incubating the testing circular samples (diameter $10 \mathrm{~mm}$ ) with three different media: PBS, 
chitotriosidase and lysozyme, at $37^{\circ} \mathrm{C}$, for the period of three weeks. The dilution factor was $9 / 11$. After treatment, the specimens were carefully washed with deionized ultrapure water to stop further enzymatic hydrolysis, and then dried under vacuum at room temperature for two days prior to biodegradation rate estimation. All measurements were performed for three replicates of samples and averaged to obtain the final result.

\subsubsection{Mechanical Properties-Tensile Strength on CsU Based Fiber Mats}

Tensile testing was performed with Instron equipment following an already described procedure [25]. In all cases the collected samples (before, after the stabilization, and acetylation procedure) were obtained after $6 \mathrm{~h} \mathrm{ESP} \mathrm{(Figure} \mathrm{1b).} \mathrm{Next,} \mathrm{they} \mathrm{were} \mathrm{cut} \mathrm{to} \mathrm{the}$ specimens with the following dimensions, $3 \mathrm{~cm}$ length $\times 0.5 \mathrm{~cm}$ width, dried overnight under vacuum without heating and placed between the jaws of the Instron. Young's modulus (MPa) and break strain (\%) were automatically calculated by Instron software (Bluehill 2, Elancourt, France). Experiments were performed at $25^{\circ} \mathrm{C}$ on the specimens with dimensions $3.0 \times 0.5 \mathrm{~cm}$, which were dried overnight under vacuum without heating.

\section{Results and Discussion}

\subsection{Electrospinning of Two-Component Water-Acidic Solutions Containing CsU and PEO}

For the preparation of micro- and nano-fibrous mats, two types of high molecular weight and medical grade chitosans (CsU) of fungus origin (CsU1 Mv 174,000 and CsU2 $\sim 205,000$, degree of deacetylation (DDA) $\sim 65 \%$, Table 1) were used for electrospinning (ESP), by using two component solutions containing CsU and PEO (Mv 900,000). Number of experiments aiming to find appropriate ESP conditions by tuning the water:acid ratio (from 95:5 to 85:15) of the CsU solutions, the concentration of the stock CsU solution (from 4.77 to $3.88 \mathrm{wt} \%$ ), as well as concentration of the stock PEO water solution (from 4.73 to $3.68 \mathrm{wt} \%$ ) and CsU:PEO ratio (from 88:12 to 50:50) were carried out. It was estimated that defect-free membranes (CN14 sample code, Figure 2a) can be successfully electrospun at $25{ }^{\circ} \mathrm{C}$, fixed 60:40 CsU/PEO ratio, using the initial concentrations of the stock PEO and CsU solutions as follows: $3.94 \mathrm{wt} \%$ (150 $\mathrm{mg}$ PEO in $3.8 \mathrm{~mL}$ water) and $4.4 \mathrm{wt} \%$ (150 mg $\mathrm{CsU}$ in $3.25 \mathrm{~mL}$ water and $0.163 \mathrm{~mL}$ acetic acid). All attempts outside these parameters to produce blended fibers easily detachable from the collector surface were not satisfied or even did not result in fiber formation.
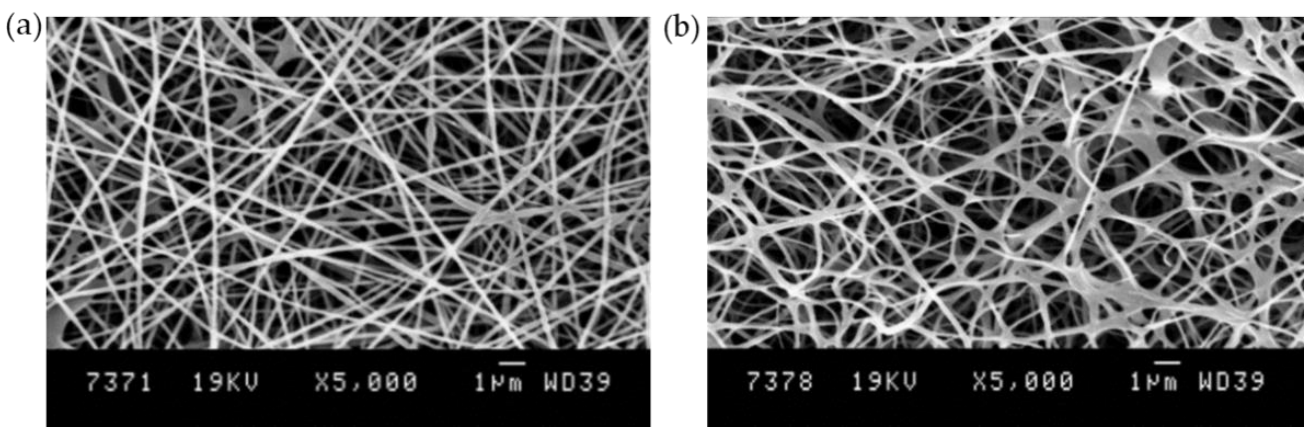

Figure 2. ESEM images of electrospun fibers from a two component solution of the chitosan (4.4 $\mathrm{wt} \%$ CsU1) and PEO (60:40 ratio) (CN14, Table 2) (a) before and (b) after stabilization and PEO removal.

Moreover, instability of the jet leading to drops with the time of the ESP, were observed. The detailed literature survey confirmed these findings [26-30]. To overcome these difficulties further, studies were carried out with addition of surfactant to $\mathrm{CsU} / \mathrm{PEO}$ ESP solution.

\subsection{ESP of Three-Component Water-Acidic Solutions Containing CsU, PEO and Triton-X 100}

Triton-X 100 is considered as a comparatively mild nondenaturing surfactant, reported in numerous references frequently used for ESP chitosan [26,27]. Addition of such nonionic 
surfactant to the CsU/PEO mixture is expected to decrease the viscosity of the polymer solution. Moreover, some plasticizing effects could open a prospect for broadening the window of electrospinning possibilities of CsU:PEO water-acidic solutions. It should be also noticed that Triton X-100 has no antimicrobial properties [27].

Following the above described preparation procedures (Scheme 2), Tables 2 and 3 show different three-component solutions containing CsU-PEO-Triton X-100, dissolved in wateracidic media. Solutions of a composition at constant 60:40 CsU:PEO ratio varying only the concentration in the range $0.5 \mathrm{wt} \% \div 0.01 \mathrm{wt} \%$ of Triton X-100 were firstly examined (Table 3). The obtained mixtures were subjected to detailed viscosity measurements at $25^{\circ} \mathrm{C}$ (Figure 3a). As a rule, increasing the surfactant content in the mixtures decreases the viscosity that dropped reaching its lower level for CN32 ESP sample containing the higher surfactant concentration $(0.5 \mathrm{wt} \%$ ) (Figure $3 \mathrm{a})$. The mixtures were electrospun and high quality mats easily detachable from the collector were obtained in all cases. In order to resolve the morphology of the as prepared fibers ESEM was performed (Figure 3b).

(a)

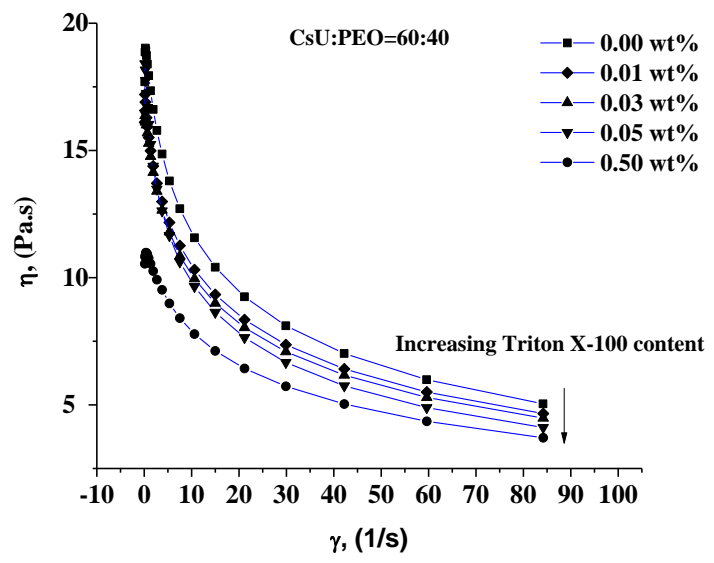

(b)

before stabilization

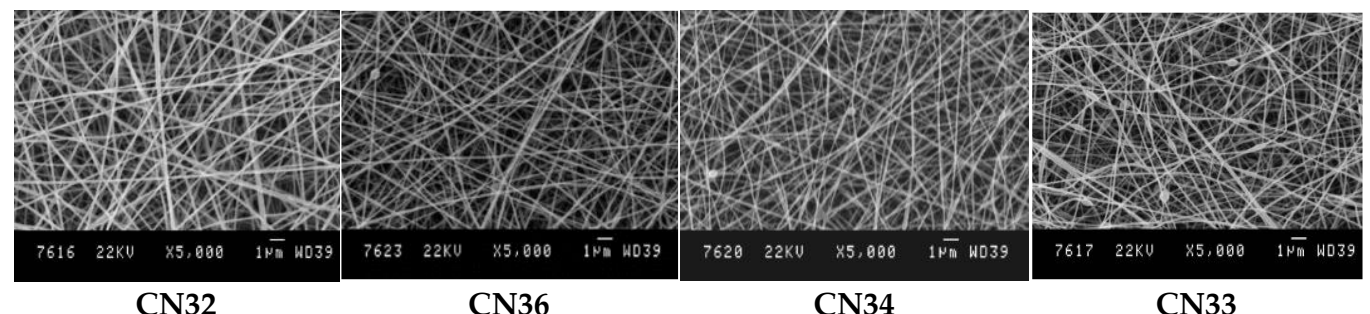

$\begin{array}{lll}0.5 & w t & \%\end{array}$ Triton X-100 $\quad 0.05 w t \%$ Triton X-100 $\quad 0.03 w t \%$ Triton X-100 $\quad 0.01$ wt $\%$ Triton X-100

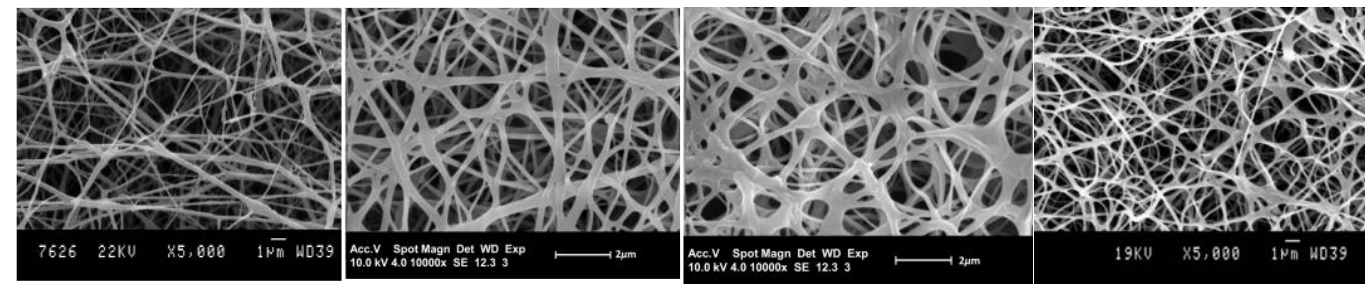

after stabilization and purification

Figure 3. Viscosity vs. shear rate (a) and ESEM image of electrospun membranes (b) for solutions of the CsU1:PEO 60:40 and various contents of Triton X (see Table 3).

Linear dependence of the mats' defects disappearance on the concentration of Triton $X$ was observed as exemplified by Figure 3b. A lot of bead defects are observed on the CN33 image, i.e., at low concentration of Triton $X$, the amount of these defects progressively decreases while increasing the concentration (CN34 and CN36 images) and completely disappear at high concentration (CN32). The decrease of the interfacial tension in presence of Triton X, notably at the air/water droplet where the jet is generated favors the electrospin- 
ning process leading to the formation of smooth and beadless nanofibrous chitosan-based mats. Moreover, the addition of surfactant decreases the viscosity of the polymer solution, reduces the onset voltage required to induce spinnability allowing polymer solution to remain spinnable over a longer period of time and thus improving reproducibility of the process. Furthermore, the obtained CsU:PEO porous mats keep their fibrillar morphology after subsequent treatment with a mixture of dry absolute ethanol EtOH/0.5 M NaOH for $5 \mathrm{~min}$ followed by three times washing with deionized water (for $5 \mathrm{~min}$ ). This procedure is applied to the collected mats in order to stabilize them in neutral aqueous media. It aims to combine two effects, i.e., the deprotonation of the $\mathrm{NH}_{3}{ }^{+}$group of the chitosan and the dissolution of the PEO and Triton X-100 resulting in pure CsU nano-fiber mats and therefore increasing the membrane stability in neutral or weak alkaline aqueous media as physiological and cell culture media, required for tissue engineering applications.

As can be seen from Figure 3, the structure of the purified and stabilized 2D scaffolds is entirely preserved. They are highly porous and without defects. Taking into account the composition, concentration of Triton X-100, viscosity measurements and quality of the mats, CN36 sample mat was selected as the one with the best characteristics (Figure 3b). The TGA and DSC profiles of the electrospun CN36 fibers before and after their deprotonation and purification were recorded and compared to the profiles of the pure CsU, and pure PEO (as a powder) (Figure 4) [15-17].
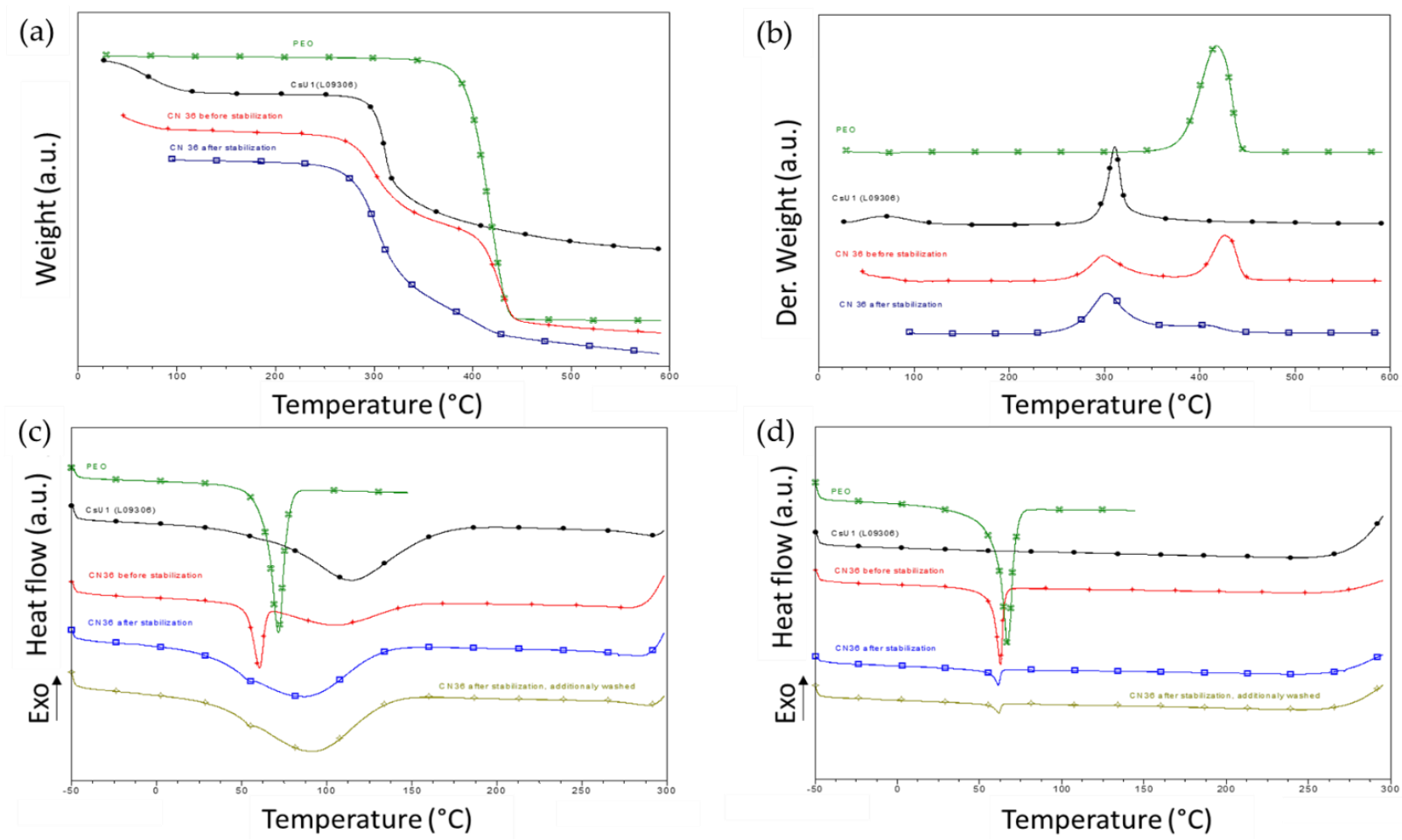

Figure 4. Thermal behavior of CsU1 (black traces), PEO (green curves), CN36 mat before (red traces) and after stabilization and purification (blue traces and grey traces after additional washing). TGA curves (a) and TGA derivatives (b); DSC curves first (c) and second (d) heating ramps.

The TGA curves of the CN36 before stabilization shows clearly two degradation steps. The first one corresponds to the degradation of $\mathrm{CsU}$ (around $300^{\circ} \mathrm{C}$ ) and the second (around $400{ }^{\circ} \mathrm{C}$ ) to the degradation of the PEO part. The TGA curves of the CN36 after stabilization shows also the main degradation step (around $300^{\circ} \mathrm{C}$ ) connected with degradation of $\mathrm{CsU}$ and one very small peak (shoulder like) around $400{ }^{\circ} \mathrm{C}$ related to the degradation of PEO traces in the mats. The stabilization process is thus able to preserve the chitosan fiber from the dissolution and to remove the main part of PEO from the electrospun mats, leading to chitosan 2D scaffolds. 
The DSC data confirm these observations. On the first heating run of the CN36 sample before stabilization, two distinct endotherms were observed. The first one corresponds to the PEO melting endotherm (around $60^{\circ} \mathrm{C}$ ). The second broad endotherm could be attributed to the evaporation of the water absorbed by CsU (around $100^{\circ} \mathrm{C}$ ). Following the fast cooling, the second heating run was started. On the recorded thermogram only one melting peak of $\mathrm{PEO}$ around $60^{\circ} \mathrm{C}$ appeared. The disappearance of the second peak (around $100{ }^{\circ} \mathrm{C}$ ) could be connected with the full elimination of the absorbed water [31]. The DSC curves of the CN36 after stabilization also displayed two main peaks at the first heating run and one (around $60^{\circ} \mathrm{C}$ ) during the second run having very low intensity.

In order to entirely remove PEO, CN36 sample was additionally washed three times with deionized water for $30 \mathrm{~min}$ and the DSC measurement was repeated. The persistence of the PEO melting peak was detected but its intensity progressively decreases i.e., the peak slowly disappeared with the washing time. However, PEO elimination from 60:40 CsU:PEO ratio compositions at washing time of $45 \mathrm{~min}$ was not complete.

In this context, the major aim of next studied compositions was to reduce the PEO content in the starting CsU:PEO mixture without affecting the produced mats' quality by finding the appropriate Triton X-100 concentration. For each of the following CsU:PEO ratios, 70:30, 80:20, 85:15, 88:12 up to 90:10, the concentration of Triton X-100 was adjusted in order to compensate for the increase of the viscosity due to the decrease of the PEO content and therefore preserve the formation of defect-free fiber mats (Table 3 and Figure 5a).

(a)

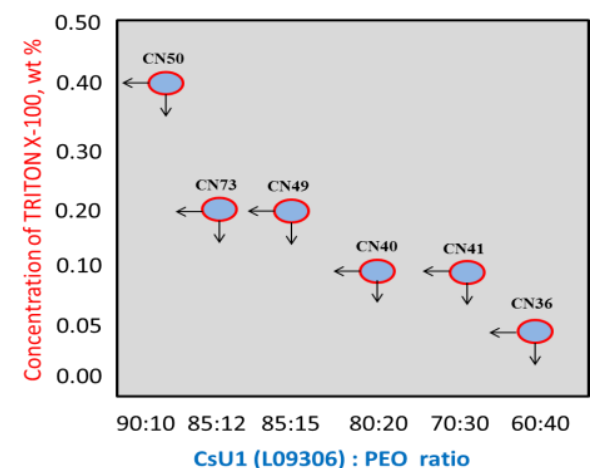

(b)

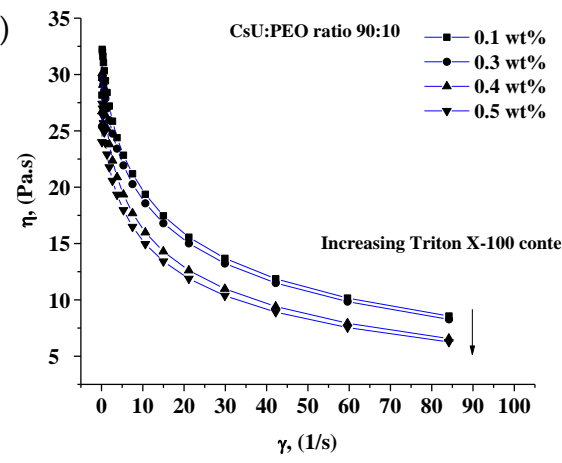

(c) before stabilization

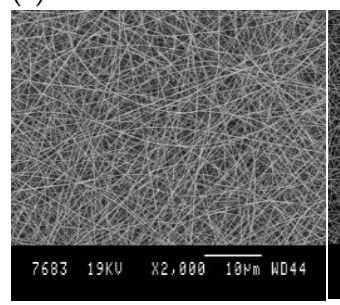

CN41 (70:30)

$0.1 \mathrm{wt} \%$ Triton $\mathrm{X}-100$

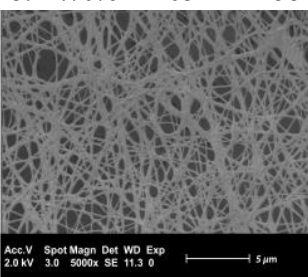

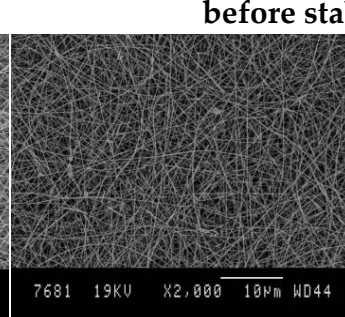

CN40 (80:20)
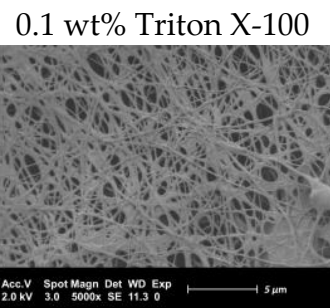

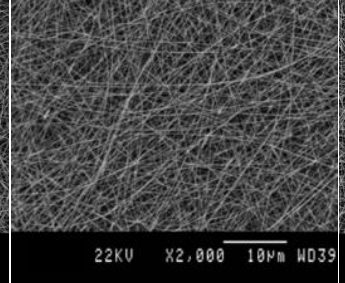

CN49 (85:15)

$0.2 \mathrm{wt} \%$ Triton X-100

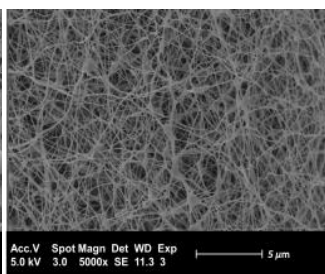

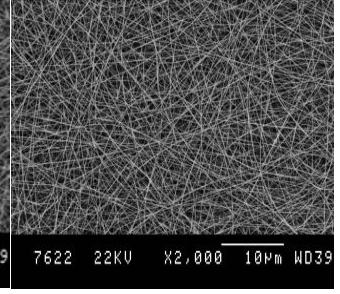

CN50 (90:10)

$0.4 \mathrm{wt} \%$ Triton $\mathrm{X}-100$

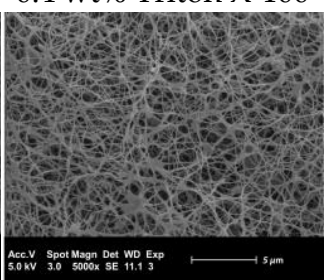

after stabilization

Figure 5. Minimal Triton X-100 concentration for achieving ESP of CsU/PEO solutions of various ratios (a); viscosity of CsU1:PEO 90:10 solutions for various Triton X-100 concentration at $25^{\circ} \mathrm{C}(\mathbf{b})$; ESEM analysis of the collected mat of the corresponding solution (Table 3) (c). 
Figure $5 \mathrm{~b}$ shows that increasing the Triton $\mathrm{X}-100$ concentration until $0.4 \mathrm{wt} \%$ allows to reach a viscosity around $5 \mathrm{~Pa} \cdot \mathrm{s}$ at $85 \mathrm{~s}^{-1}$ for a solution containing as low as $10 \%$ of PEO therefore leading to well-defined fiber mats. The most appropriate concentrations of Triton X-100 for each composition are given in Figure 5a. The criteria used were the stability of the jet during the ESP, the quality of the obtained mats and their porous fiber morphology evidenced by ESEM (Figure $5 c$ ).

The mats obtained consist of well-defined fibers and are highly porous before and after the stabilization. Both TGA and DSC measurements of CN49 mat sample (Figure 6) evidenced the decrease of the PEO content in the fiber and its quasi-complete removal after the stabilization step for $15 \mathrm{~min}$.
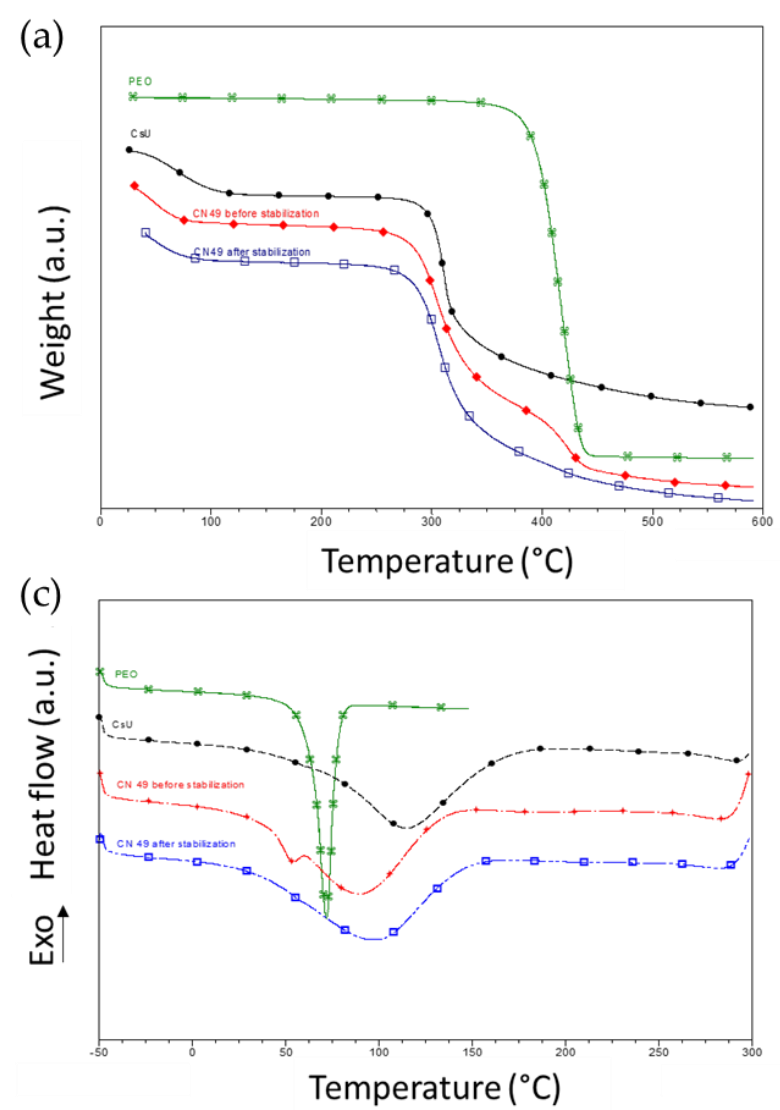

(b)
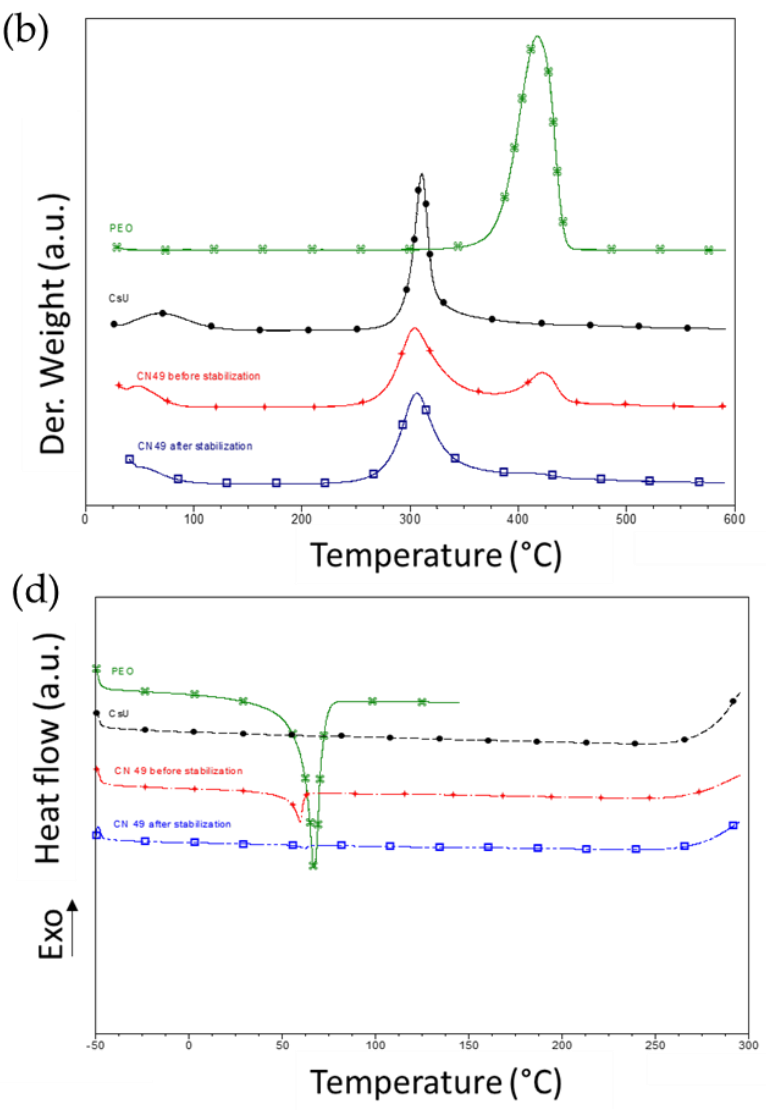

Figure 6. Thermal behavior of CsU1 (black traces), PEO (green curves), CN49 mat before (red traces) and after (blue traces) stabilization and purification. TGA curves (a) and TGA derivatives (b); DSC curves first (c) and second (d) heating ramps.

By applying the three-component solution approach and the outlined ESP limits (determined for CsU1 type), well defined nano-fibrous mats based on CsU2 of higher molar mass and viscosity were obtained revealing the robustness of these conditions. The best compositions and ESP parameters are summarized in Table 2. The collected highquality mats based on CsU2 (L10204) were characterized by ESEM analyses before and after stabilization (Figure 7). The obtained 2D scaffolds before as well as after stabilization are free of any kind of defects as drops, beads, holes, etc. 

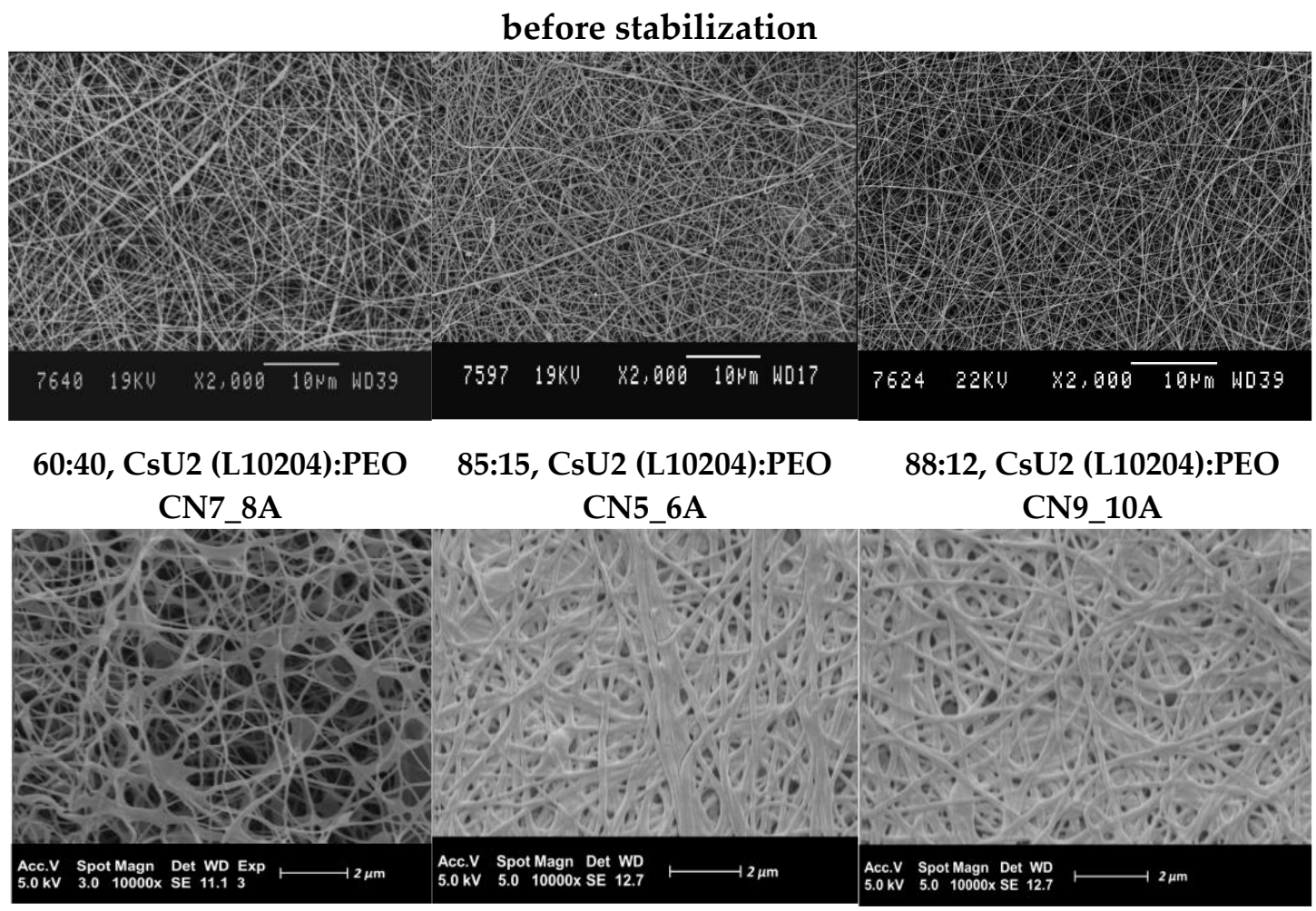

after stabilization and purification

Figure 7. ESEM analysis of CsU2 (L10204) based mats.

The most important advantage of the proposed three-component ESP is that, with small adjustments of the surfactant concentration, $\mathrm{CsU}$ of different molecular weights with close DDA can be successfully electrospun with a low content of PEO. Moreover, the PEO can be entirely removed by the described washing/stabilization process.

\subsection{Reacetylation of the Electrospun Chitosan Mats into Chitin Nanofiber Mats}

In order to tune the mechanical and degradation properties of the nanofiber mats, the conversion of chitosan into chitin by reacetylation of the electrospun mats based on high molecular weight CsUs was investigated. Indeed, such reacetylation process gives the opportunity to obtain nanofibers of chitin that are difficult to get directly by ESP since chitin is poorly soluble in most solvents. For that purpose, the CN73 (CsU1 (L09306), 82:12 CsU:PEO ratio, $0.2 \mathrm{wt} \%$ Triton X-100) and CN9_10 (CsU2 (L10204), 88:12 CsU:PEO ratio, $0.2 \mathrm{wt} \%$ Triton $\mathrm{X}-100)$ electrospun and stabilized samples were immersed in a methanol solution of acetic anhydride (see Scheme 3. In this medium, the membranes did not dissolve and the amine groups of the chitosan can be acetylated again and thus converted back from chitosan into chitin. After, applying the acetylation treatment, the membranes were additionally washed and dried by previous established procedure (see Section 2.2.3, Scheme 3). Then, they were analyzed by ESEM that evidenced the successful conservation of their fibrous structure (Figure 8). 


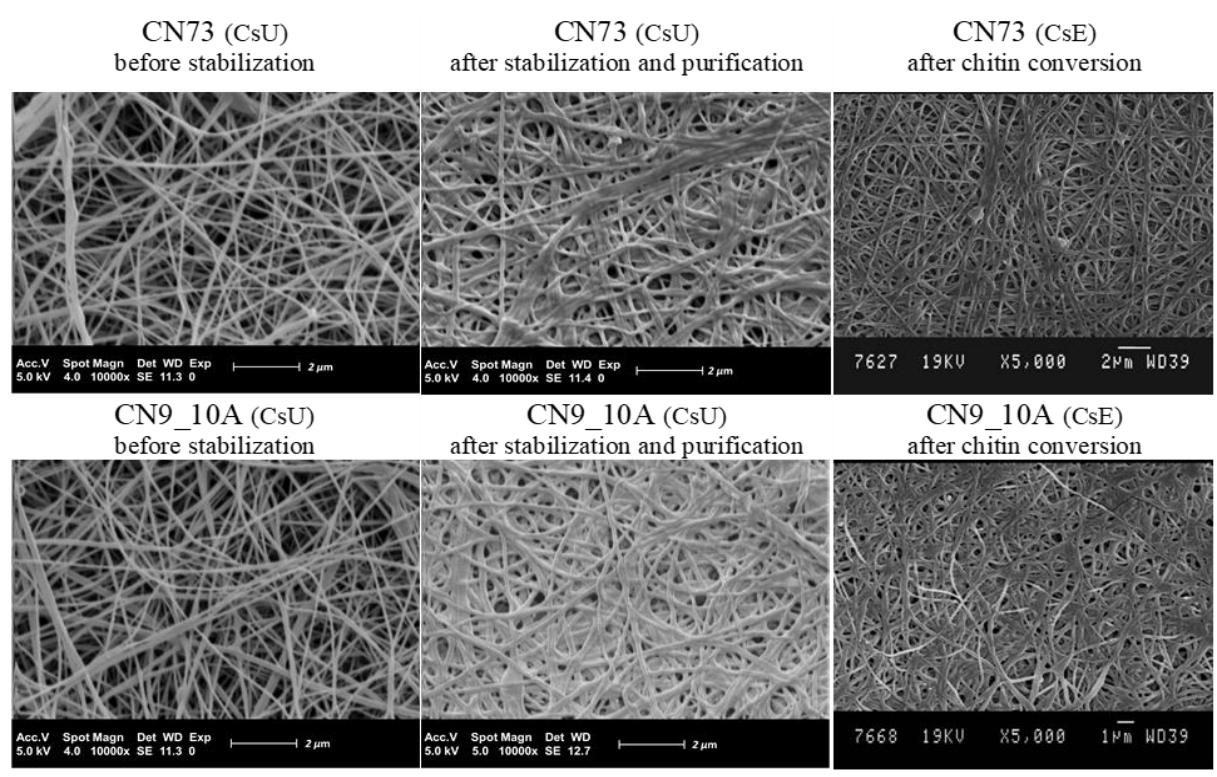

Figure 8. ESEM analysis of electrospun CsU1 and CsU2 mats before, after stabilization and after reacetylation.

First indication of the chitosan-based membranes' reacetylation into chitin is a clear change of their solubility in dilute acidic aqueous conditions. Indeed, while the chitosan mats are quickly dissolved in these conditions, after the chemical modification of the amine groups, the mats resist solubilization, as it is expected for chitin. The reaction occurrence was additionally supported by the improvement of the fiber mats' thermal stability after reacetylation (Figure 9).

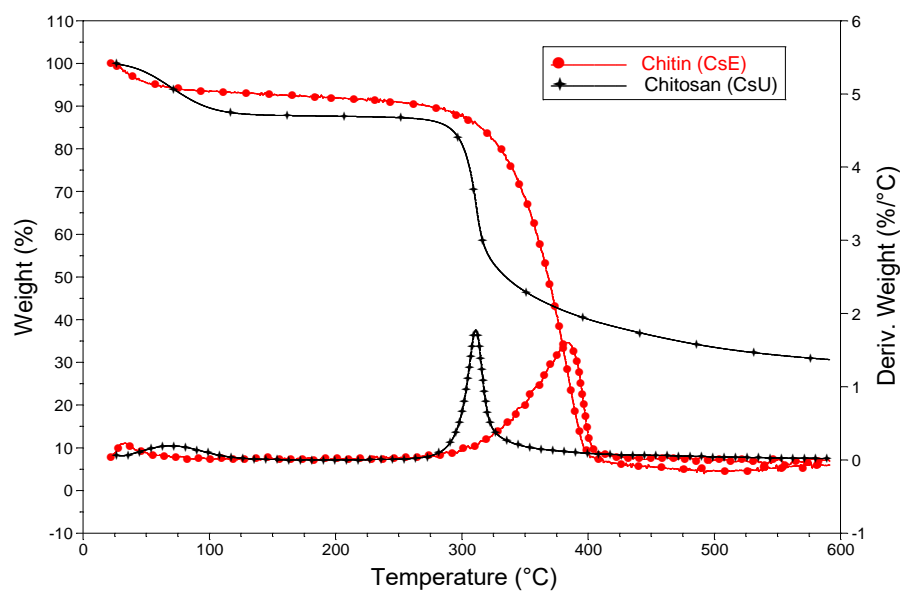

Figure 9. TGA analysis of electrospun CsU1 mat before (black) and after (red) reacetylation.

Since a higher thermal stability is observed when the N-acetyl content increases as well as the crystallinity [10], one may conclude that chitosan nanofibers have been successfully converted back into chitin ones [20,32].

\subsection{Biodegradation Properties of the Nanofiber Mats}

These polysaccharide mats are expected to be quite stable in PBS buffer but rather sensitive towards enzymatic degradation [33]. Therefore, we tested the hydrolytic stability of the chitin and chitosan mats in PBS buffer and compared this to data obtained in the presence of two enzymes: Human 3-Chitotriosidase (HCHT) and Lysozyme. The biotransformation of chitosan and chitin fibrous mats was observed only in the presence of HCHT enzyme (Figure 10). The detected weight losses were more than $90 \%$ for chitin 
specimens and around $87 \%$ for chitosan ones. HCHT is able to hydrolyze both chitin and chitosan via an endoprocessive mechanism. The preferences of HCHT subsites for acetylated (chitin) versus nonacetylated (chitosan) sugars confirmed that the catalytic activity of the enzyme on chitin is major compared to the catalytic activity on chitosan. Nevertheless, the difference of their catalytic efficiency does not exceed a factor of 10 . After 3 weeks of incubation, both materials being highly degraded, no major difference between the two polymers is observed. In the presence of Lysozyme, the degradation was not detected for both investigated samples. The latter is expected, as it is well known that the biotransformation of high molecular chitin membranes with Lysozymes proceeds very slowly [34]. In addition, the Lysozymes primarily affect the chitin component in the chitosan-based materials, hence they are poorly degradable, which is with good agreement with the presented data in Figure 10 [35-37].

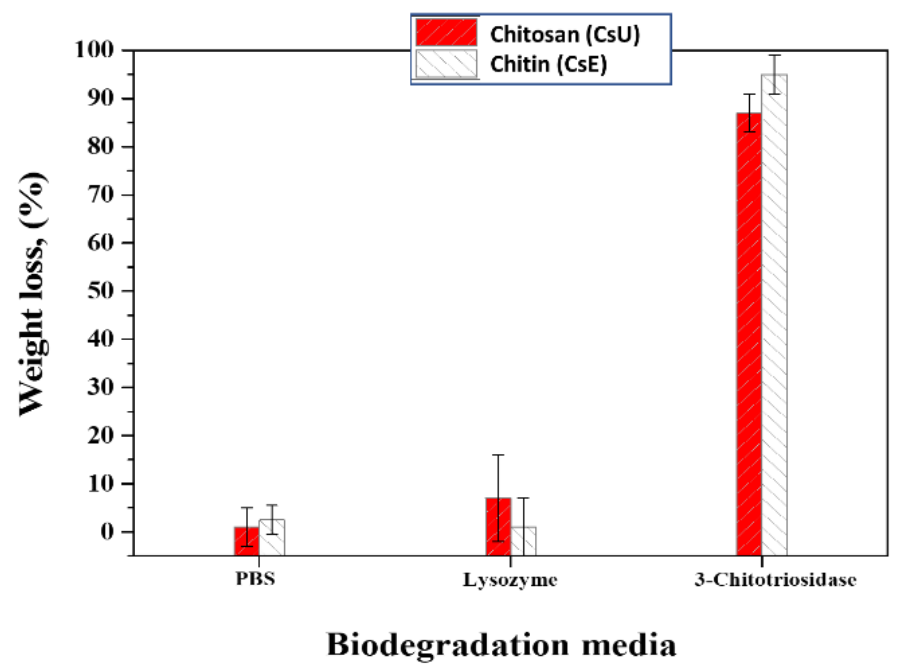

Figure 10. Biodegradation of CsU1 (L09306) based stabilized membranes and its derivate chitin (CsE) based membranes in different media for a period of three weeks.

\subsection{Mechanical Properties Evaluation}

The mechanical properties of different types of samples, i.e., ESP chitosan mats obtained before, after stabilization and chitin conversion were investigated. Tensile testing data are summarized in Table 4. The Young's modulus is one of the most crucial factors for fiber performance evaluation [18]. As a rule, comparing the mats before and after the stabilization, the Young's modulus increases after the stabilization i.e., the chitosan deprotonation and PEO removal. A slight decrease around $10 \%$ of the tensile stress and strain at break was detected (Table 4). Remarkably, the mechanical strength of the chitosan mats obtained after stabilization reaches similar values as those after reacetylation, i.e., made of chitin. These results show that the stabilization process allows getting comparable mechanical properties values for chitosan and chitin 2D biomimetic scaffolds which have made them ideal candidates for their further biomedical application, especially as scaffolds for skin regeneration [26,38]. 
Table 4. Tensile properties of the electrospun chitosan (CsU) nanofiber mats before and after stabilization, and after reacetylation (CsE conversion).

\begin{tabular}{|c|c|c|c|c|c|}
\hline $\begin{array}{c}\text { Sample } \\
\text { Code }\end{array}$ & $\begin{array}{c}\text { Type of } \\
\text { CsU } \\
\text { Used }\end{array}$ & $\begin{array}{c}\text { Initial } \\
\text { CsU:PEO } \\
\text { Ratio }\end{array}$ & $\begin{array}{l}\text { Young's } \\
\text { Modulus * } \\
\text { (MPa) }\end{array}$ & $\begin{array}{l}\text { Tensile } \\
\text { Stress at } \\
\text { Break * } \\
(\mathrm{MPa})\end{array}$ & $\begin{array}{l}\text { Tensile } \\
\text { Strain at } \\
\text { Break* } \\
(\%)\end{array}$ \\
\hline \multicolumn{6}{|c|}{ Before Stabilization and Purification (bs) CsU } \\
\hline $\mathrm{CN} 36_{\text {bs }}$ & CsU1 & $60: 40$ & $155 \pm 22$ & $6.99 \pm 0.13$ & $8.55 \pm 1.63$ \\
\hline CN64_65 bs & (L09306) & $85: 15$ & $79 \pm 22$ & $2.12 \pm 0.23$ & $2.99 \pm 0.83$ \\
\hline CN7_8A bs & & $60: 40$ & $114 \pm 18$ & $11.27 \pm 2.81$ & $20.81 \pm 7.8$ \\
\hline CN5_6A bs & CsU2 & $85: 15$ & $147 \pm 19$ & $10.98 \pm 1.47$ & $14.70 \pm 1.51$ \\
\hline CN9_10A bs & & $88: 12$ & $147 \pm 21$ & $9.49 \pm 0.97$ & $12.32 \pm 1.79$ \\
\hline \multicolumn{6}{|c|}{ After Stabilization and Purification (as) CsU } \\
\hline $\mathrm{CN} 36$ as & CsU1 & $60: 40$ & $181 \pm 25$ & $7.54 \pm 0.97$ & $10.44 \pm 4.85$ \\
\hline CN64_65 as & (L09306) & $85: 15$ & $125 \pm 19$ & $3.36 \pm 0.53$ & $3.67 \pm 1.36$ \\
\hline CN7_8A as & & $60: 40$ & $191 \pm 34$ & $10.70 \pm 2.01$ & $16.75 \pm 4.37$ \\
\hline CN5_6A as & $\mathrm{CsU} 2$ & $85: 15$ & $276 \pm 31$ & $10.70 \pm 0.87$ & $10.87 \pm 1.18$ \\
\hline CN9_10A as & (L10204) & $88: 12$ & $224 \pm 22$ & $9.14 \pm 0.22$ & $9.97 \pm 1.08$ \\
\hline \multicolumn{6}{|c|}{ After Reacetylation(ar) CsE } \\
\hline CN9_10A ar & $\begin{array}{c}\text { CsU2 } \\
\text { (L10204) }\end{array}$ & $88: 12$ & $216 \pm 23$ & $7.56 \pm 0.35$ & $8.44 \pm 0.95$ \\
\hline
\end{tabular}

* The values presented are averaged from five experiments at standard deviation.

\section{Conclusions}

Well-defined and stable chitosan based 2D biomimetic scaffolds mats were successfully prepared by reproducible ESP of high molecular weight and medical grades CsUs in the presence of PEO and given amounts of Triton X-100 as surfactant. The Triton X-100 addition combines several advantages. The sensitivity of the ESP was successfully overcome. Thus, the concentration of $\mathrm{CsU}$ in the starting CsU:PEO ratio was easily varied. Finally, the surfactant addition allows getting nano-fibrous membranes at high CsU content (up to 90\%) from which PEO is easily removed. The proposed stabilization and purification approach provided long-term water and physiological media stability and entirely PEO removal from the as-spun CsU membranes preserving at the same time the initial nanofiber morphology. It was achieved by simple neutralization, without any use of chemical cross-linkers or chlorine-containing organic solvents. Remarkably, the stabilized chitosan nanofiber mats, exempt from PEO, exhibit high Young's modulus and improved mechanical properties, making them suitable for handling in medical applications.

Furthermore, acetylation procedure was investigated and proved to be effective to adjust the solubility, the thermal and the enzymatic stability of the nanofiber mats by converting chitosan mats into chitin ones. In other words, the proposed reaction strategy allowed preparation of well-defined chitosan and chitin nanofibrous mats with predefined mechanical properties and biodegradation abilities (fast enzymatic biodegradation in some cases and slower on the others). The latter can be extremely useful towards a variety of biomedical purposes as in a wound dressing field and/or tissue engineering.

Author Contributions: Conceptualization, C.J. and M.G.; methodology, A.A. and C.J.; validation, N.T.-M., A.A. and C.J.; formal analysis, A.A.; investigation, N.T.-M.; resources, C.J. and M.G.; data curation, A.A., and C.J.; writing-original draft preparation, N.T.-M.; writing-review and editing, A.A., C.J. and M.G.; supervision, A.A. and C.J.; project administration, C.J.; funding acquisition, C.J. All authors have read and agreed to the published version of the manuscript.

Funding: The present work was supported by the Science Policy Office of the Belgian Federal Government (IAP 7/05). CERM thanks the Walloon Region for supporting research on chitosan in the frame of CHITOPOL, TARGETUM, GOCELL and HOMECELL projects. CIP thanks the Walloon Region for supporting research in the frame of GOCELL and HOMECELL. 
Institutional Review Board Statement: Not applicable.

Informed Consent Statement: Not applicable.

Data Availability Statement: Not applicable.

Conflicts of Interest: The authors declare no conflict of interest.

\section{References}

1. Croisier, F.; Jérôme, C. Chitosan-based biomaterials for tissue engineering. Eur. Polym. J. 2013, 49, 780-792. [CrossRef]

2. Pillai, C.K.S.; Sharma, C.P. Electrospinning of chitin and chitosan nanofibers. Trends Biomater. Artif. Organs 2009, $22,179-201$.

3. Majeti, N.V.; Kumar, R. A review of chitin and chitosan applications. React. Funct. Polym. 2000, 46, 1-27.

4. Kannan, M.; Nesakumari, M.; Rajarathinam, K.; Ranjit Singh, A.J.A. Production and characterization of mushroom chitosan under solid-state fermentation conditions. Adv. Biol. Res. 2010, 4, 10-13.

5. Madihally, S.V.; Howard, M.W.T. Porous chitosan scaffolds for tissue engineering. Biomaterials 1999, 20, 1133-1142. [CrossRef]

6. Nisbet, D.R.; Forsythe, J.S.; Shen, W.; Finkelstein, D.I.; Horne, M.K. Review paper: A review of the cellular response on electrospun nanofibers for tissue engineering. J. Biomater. Appl. 2009, 24, 7-29. [CrossRef]

7. Pillai, C.K.S.; Paul, W.; Sharma, C.P. Chitin and chitosan polymers: Chemistry, solubility and fiber formation. Prog. Polym. Sci. 2009, 34, 641-678. [CrossRef]

8. Homayoni, H.; Ravandi, S.A.H.; Valizadeh, M. Electrospinning of chitosan nanofibers: Processing optimization. Carbohydr. Polym. 2009, 77, 656-661. [CrossRef]

9. Ohkawa, K.; Minato, K.-I.; Kumagai, G.; Hayashi, S.; Yamamoto, H. Chitosan Nanofiber. Biomacromolecules 2006, 7, 3291-3294. [CrossRef] [PubMed]

10. Desai, K.; Kit, K.; Li, J.; Zivanovic, S. Morphological and surface properties of electrospun chitosan nanofibers. Biomacromolecules 2008, 9, 1000-1006. [CrossRef] [PubMed]

11. Zhang, Y.Z.; Su, B.; Ramakrishna, S.; Lim, C.T. Chitosan Nanofibers from an easily electrospinnable UHMWPEO-Doped chitosan solution system. Biomacromolecules 2008, 9, 136-141. [CrossRef]

12. Haider, S.; Park, S.-Y. Preparation of the electrospun chitosan nanofibers and their applications to the adsorption of Cu(II) and $\mathrm{Pb}$ (II) ions from an aqueous solution. J. Membr. Sci. 2009, 328, 90-96. [CrossRef]

13. Sill, T.J.; Recum, H.A. Electrospinning: Applications in drug delivery and tissue engineering. Biomaterials 2008, 29, 1989-2006. [CrossRef]

14. Ignatova, M.; Manolova, N.; Rashkov, I. Novel antibacterial fibers of quaternized chitosan and poly(vinyl pyrrolidone) prepared by electrospinning. Eur. Polym. J. 2007, 43, 1112-1122. [CrossRef]

15. Jayakumar, R.; Prabaharan, M.; Nair, S.V.; Tamura, H. Novel chitin and chitosan nanofibers in biomedical applications. Biotechnol. Adv. 2010, 28, 142-150. [CrossRef] [PubMed]

16. Jayakumar, R.; Menon, D.; Manzoor, K.; Nair, S.V.; Tamura, H. Biomedical applications of chitin and chitosan based nanomaterials -A short review. Carbohydr. Polym. 2010, 82, 227-232. [CrossRef]

17. Sogias, I.A.; Khutoryanskiy, V.V.; Williams, A.C. Exploring the factors affecting the solubility of chitosan in water. Macromol. Chem. Phys. 2010, 211, 426-433. [CrossRef]

18. Sarmento, B.; Neves, J. Chitosan-Based Systems for Bbiopharmaceuticals: Delivery, Targeting and Polymer Therapeutics, 1st ed.; John Wiley \& Sons: Hoboken, NJ, USA, 2012.

19. De Vrieze, S.; Van Camp, T.; Nelvig, A.; Hagstrom, B.; Westbroek, P.; De Clerck, K. The effect of temperature and humidity on electrospinning. J. Mater. Sci. 2009, 44, 1357-1362. [CrossRef]

20. Nam, Y.S.; Park, W.H.; Daewoo, I.; Hudson, S.M. Effect of the degree of deacetylation on the thermal decomposition of chitin and chitosan nanofibers. Carbohydr. Polym. 2010, 80, 291-295.

21. Bhardwaj, N.; Kundu, S.C. Electrospinning: A fascinating fiber fabrication technique. Biotechnol. Adv. 2010, $28,325-347$. [CrossRef]

22. Riva, R.; Ragelle, H.; des Rieux, A.; Duhem, N.; Jérôme, C.; Preat, V. Chitosan and chitosan derivatives in drug delivery and tissue engineering. Adv. Polym. Sci. 2011, 244, 19-44.

23. Sathiyaseelan, A.; Shajahan, A.; Kalaichelvan, P.T.; Kaviyarasan, V. Fungal chitosan based nanocomposites sponges-An alternative medicine for wound dressing. Int. J. Biol. Macromol. 2017, 104, 1905-1915. [CrossRef] [PubMed]

24. Sathiyaseelan, A.; Kalaichelvan, P.T. Application of tetracycline hydrochloride loaded-fungal chitosan and Aloe vera extract based composite sponges for wound dressing. J. Adv. Res. 2018, 14, 63-71.

25. Dutta, P.K.; Rinki, K.; Dutta, J. Chitosan: A Promising Biomaterial for Tissue Engineering Scaffolds. In Chitosan for Biomaterials II; Jayakumar, R., Prabaharan, M., Muzzarelli, R., Eds.; Advances in Polymer Science; Springer: Berlin/Heidelberg, Germany, 2011; Volume 244, pp. 45-80.

26. Ziani, K.; Henrist, C.; Jerome, C.; Aqil, A.; Maté, J.I.; Cloots, R. Effect of nonionic surfactant and acidity on chitosan nanofibers with different molecular weights. Carbohydr. Polym. 2011, 83, 470-476.

27. Kriegel, C.; Kit, K.M.; McClemens, D.J.; Weiss, J. Electrospinning of chitosan-poly(ethylene oxide) blend nanofibers in the presence of micellar surfactant solutions. Polymer 2009, 50, 189-200. [CrossRef] 
28. Pepić, I.; Filipović-Grčić, J.; Jalšenjak, I. Interactions in a nonionic surfactant and chitosan mixtures. Colloids Surf. A Physicochem. Eng. Asp. 2008, 327, 95-102. [CrossRef]

29. Sangsanoh, P.; Supaphol, P. Stability improvement of electrospun chitosan nanofibrous membranes in neutral or weak basic aqueous solutions. Biomacromolecules 2006, 7, 2710-2714. [CrossRef]

30. Luu, Y.K.; Kim, K.; Hsiao, B.S.; Chu, B.; Hadjiargyrou, M. Development of a nanostructured DNA delivery scaffold via electrospinning of PLGA and PLA-PEG block copolymers. J. Control. Release 2003, 89, 341-353. [CrossRef]

31. Peter, M.G. Chitin and chitosan in fungi. In Biopolymers, Online ed.; Steinbüchel, A., Ed.; Wiley-VCH Verlag GmbH: Weinheim, Germany, 2005; Part 6; pp. 123-132.

32. Corazzari, I.; Nistico, R.; Turci, F.; Faga, M.G.; Franzoso, F.; Tabasso, S.; Magnacca, G. Advanced physico-chemical characterization of chitosan by means of TGA coupled on-line with FTIR and GCMS: Thermal degradation and water adsorption capacity. Polym. Degrad. Stab. 2015, 112, 1-9. [CrossRef]

33. Salas, C.; Thompson, Z.; Bhattarai, N. 15-Electrospun chitosan fibers. In Electrospun Nanofibers; Afshari, M., Ed.; Elsevier: Cambridge, UK, 2017; pp. 371-398.

34. Han, T.; Nwe, N.; Furuike, T.; Tokura, S.; Tamura, H. Methods of N-acetylated chitosan scaffolds and it's in vitro biodegradation by lysozyme. J. Biomed. Sci. Eng. 2012, 5, 15-23. [CrossRef]

35. Gorzelanny, C.; Pöppelmann, B.; Pappelbaum, K.; Moerschbacher, B.M.; Schneider, S.W. Human macrophage activation triggered by chitotriosidase-mediated chitin and chitosan degradation. Biomaterials 2010, 31, 8556-8563. [CrossRef] [PubMed]

36. Kean, T.; Thanou, M. Biodegradation, bio distribution and toxicity of chitosan. Adv. Drug Deliv. Rev. 2010, 62, 3-11. [CrossRef]

37. Croisier, F.; Atanasova, G.; Poumay, Y.; Jérôme, C. Polysaccharide-Coated PCL nanofibers for wound dressing applications. Adv. Healthc. Mater. 2014, 3, 2032-2039. [CrossRef] [PubMed]

38. Tchemtchoua, V.T.; Atanasova, G.; Aqil, A.; Filee, P.; Garbacki, N.; Vanhooteghem, O.; Deroanne, C.; Noel, A.; Jerome, C.; Nusgens, B.; et al. Development of a Chitosan Nanofibrillar Scaffold for Skin Repair and Regeneration. Biomacromolecules 2011, 12, 3194-3204. [CrossRef] [PubMed] 